\title{
Research on the Translation of Ancient Books
}

\author{
Siyu Zou \\ Nanchang Institute of Technology
}

\begin{abstract}
Keywords: English Translation; Ancient Book Translation; Translation Principles
\end{abstract}
\begin{abstract}
Modern Chinese English translation catalyzed by Robert Morrison early Anglo American Protestant missionaries, early Protestant Missionaries Westerners to Chinese penetration and highlight the advantages of Western Christian culture of the main media. Due to the English translation involves both in English and Chinese language and culture, are not familiar with Chinese Protestant Missionaries Westerners in translation just have to rely on the assistance of the Chinese people. With the transformation of modern Chinese society, Chinese people continue to deepen the English translation of the western science movement in awareness of the importance of gradually from passivity to initiative, from subordination to independent, the emergence of a group like Ma Jian Zhong, Yan Fu, Lin Shu, Liang Qichao, a famous translation theory and Translation master, constructing the modern Chinese English translation of an important force. But there is also a series of problems in China. This paper examines the translation of ancient significance, principle, the choice of the original text, translation style, quality of personnel and other issues.
\end{abstract}

\section{Introduction}

Translation is a subject for the study of absorbing anything and everything. We cannot do without the object of translation for the translation and the original alignment. In the process of translation, many translators will exhibit considerable arbitrariness, especially in the choice and application of sentences, words and slang, showing quite selective tendency, according to the use of language, choose a variety of linguistic patterns combined with the way of translation. Linguistics contains the surface to be broad, both from the structure, function, culture, or from the point of view of the context, the translator in the translation process will interact alignment, and by the influence of translator's theoretical level and brainstorming is deep. In the oral translation, the translator for the linguistic model are used and very fast, usually for the original structure, the translation object and context need only have a certain understanding, and in the translation process, the linguistic model of the selection and application requirements are much more. It hosts the translator to refine the structure and content of the original text and the target text on the basis of time, so as to make the translation content conform to the reader's cognitive habits. This requires the translator to understand clearly the object of the original text and the translation habits of thinking and language features, and the choice of language use have an in-depth study, only in this way means or to a complete description of the original.

\section{The Use of Linguistic Views and Various Linguistic Models in the Process of Translation}

From the present translation model, the translation of English is still the highest translation approach, and the research of Chinese translation theory is based on the theory of linguistics. At present, there are several theories in Chinese translation circle:

Semantic Model. Semantics is an important branch of the linguistic model, and it is also the most widely used and persistent theory. From the 1980s to the early 1990s, the development of semantics is very rapid, especially after the western modern linguistic theory was introduced into China, combined with the original semantic translation theory, and has quickly become one of the important theoretical factions in Chinese translation field.

Pragmatics Model. The theory of pragmatics is utilized more and more widely in our country, and it is also increasing year by year. At present, China's most popular and influential pragmatic theory is context theory and relevance theory, adaptation theory, behavior theory, cooperation 
theory and the theory of Memetic and so on. In addition, influence of domestication and Foreignization in translation is also very great.

Cognitive Linguistic Model. Cognitive linguistic model is a type of "Re Processing" model of translation. At first for a deeper understanding of the entire, especially for vocabulary use and combination rules of sentence structure, paragraph level etc. Were studied, trying to find the original writing rules or language application rules and with these characteristics in cognitive and to identify with the universal law of translation strategies. Cognitive linguistics model emphasizes the universality and practicality, is to try to translate from a cognitive perspective.

\section{Deficiencies of Ancient Books}

Deficiencies in Language. Translation activities cannot be separated from the perspective of the translator's understanding of the meaning of the original text. Understanding is the foundation of expression, only the correct understanding, to be faithful to the meaning of expression. Although professor Luo Mushi as a Chinese doctor of Columbia University, the Chinese language skills are more profound, but Chinese is not in mother tongue after all, misreading is inevitable.

Deficiencies in Cultural. Cultural context and translation in the process of translation should pay great attention to cultural context factors. This is because the different cultural background may make the use and expression of language and collocation is very different. In the process of translation, the translator should skillfully deal with the cultural differences between the original and the target text, to make sure that the target language can be more accurate and the meaning of the source language works.

Mistranslation Caused by Improper Grammatical Structure Understanding. The meaning of a single word and phrase is well understood, but it is worrying that they lack the basic understanding of the ways in which they are constructed. Fuzzy thinking of Han nationality makes Chinese showing characteristics of parataxis, words or sentences connected mainly with the logical relationship between semantic or statement to achieve, loose sentences, syntactic function of recessive, the relational connecting words, prepositions, pronouns, limited words or composition of attributive and adverbial than in English are very little.

\section{Principles of Ancient Books Translation}

To be involved in the translation of ancient books, as well as other translation work, must follow certain principles. The basic principle of faithfulness, expressiveness and elegance are regarded, as the translation of an ancient Chinese translation should follow this principle. To carefully follow the "3 properties" principle of translation work, and ensure the translation works of "faithfulness, expressiveness and elegance", the following specific principles are put forward according to the actual situation of the translation work of ethnic ancient books:

Integrity Principle. Whether translation monograph or translation of a series, from beginning to end all translation. Only in this way, can make the reader understand the imaginative picture. Avoid by all means is from personal likes and dislikes of those who believe that this is not important or not interested, even that is dross, bowdlerization or processing.

Authenticity Principle. On ethnic antique books of translation to "3 properties" have, namely, authenticity, distinct, art of, also known as the "faithfulness, expressiveness and elegance". The authenticity is the most fundamental condition.

Accuracy Principle. Ethnic ancient books of writing time ago few hundreds of years, more than a thousand years, the account of the historical and cultural as compared with today's knowledge, is bound to have great difference; plus, the ancients to copy the words chaos, many variant spelling book, may not be clear at a glance. 


\section{Conclusion}

In the process of the study of linguistics, it forms a pragmatic study, which focuses on how to use the language, especially for the specific words and meanings of the exact situation. In the process of translation study on Application of pragmatics, for translation in the field of innovation of the research methods, so as to enhance its vitality, the linguists can from a new point of view to discuss the translation of contradictions and problems, to ensure that the original and the translation of pragmatic equivalence. ancient Chinese book translation for the current stage of the development of translation theory plays an unparalleled role. I believe that the translation of ancient books in the next period of time will continue to be a very important role in China's translation.

\section{Acknowledgements}

Project funding:Social science planning project of Jiangxi Province in 2013 (Research on cultural default and its compensation based on interpretive translation theory, Id: 13YY22)

\section{References}

[1] Morini M. FROM NORMS TO MACRO-NORMS? Translation of Classics seen in a Global, Diachronic Framework [J]. Lange E Linguaggi, 2014.

[2] Jian-Jun L I. Transferability of Traditional Culture and Its Translation Strategies in the Translation of Classics into English [J]. Journal of Anhui University of Technology, 2014.

[3] Wang L. English Translation of Classics and Cross-Cultural Communication of Confucianism [J]. Guan Zi Journal, 2008.

[4] Song H Y. Translation of Classics of Central Chinese Traditional Culture from the Perspective of Eco-Translatology [J]. Journal of Harbin University, 2014.

[5] Jiang F. Bring Marco Polo Back to China: Feng Chengjun and His Translation of Classics about Sino-Foreign Cultural Exchanges [J]. Chinese Translators Journal, 2006.

[6] Weber A. Thierry Meynard S. J. (Hg.): Confucius Sinarum Philosophus (1687): The First Translation of the Confucian Classics, Rom: Institutum Historicum Societatis Iesu 2011, 449 S.[J]. Zeitschrift für Religions- and Geistesgeschichte, 2014, 66(2) :189-191.

[7] Yi-Min L E, Hua X U. Translation of Classics In TCM Bilingual Teaching: Its Practice and Exploitation [J]. Journal of Jiangxi University of Traditional Chinese Medicine, 2010.

[8] Meynard T, Intorcetta P. Confucius Sinarum philosophers (1687): the first translation of the Confucian classics [M]. Instituted Historicum Societatis Iesu, 2011.

[9] Zhao G, Liu X. Three Models of Equivalence in English Translation of Chinese Classics in the Light of the Theory of Translation as Selection and Adaptation [J]. Journal of Language Teaching \& Research, 2011, 2(1).

[10]Fan L. On the Problem of Classics Translation Practice [J]. Journal of Jiaozuo University, 2012.

[11]Jiang X, Zhao L, Wu D. A Study on Machine Translation of Register-Specific Terms in Tea Classics [C]/ 2009 WASE International Conference on Information Engineering. IEEE Computer Society, 2009:57-60.

[12]Lin W. Some thoughts on the translation of chinese classics [J]. Other Words the Journal for Literary Translators, 1997: págs. 68-71. 